\title{
Iris rubeosis and hyphema caused by chemical injury due to household detergent
}

This article was published in the following Dove Press journal:

Clinical Ophthalmology

27 November 2012

Number of times this article has been viewed

\author{
Chikako Suto ${ }^{1,2}$ \\ Tetsuya Ishizuka' \\ Hiroshi Toshida ${ }^{3}$ \\ 'Department of Ophthalmology, \\ Saiseikai Kurihashi Hospital, \\ Kuki, Saitama, ${ }^{2}$ Department of \\ Ophthalmology, Tokyo Women's \\ Medical University, Shinjuku, Tokyo, \\ ${ }^{3}$ Department of Ophthalmology, \\ Juntendo University Shizuoka \\ Hospital, Izunokuni, Shizuoka, Japan
}

Correspondence: Chikako Suto Department of Ophthalmology, Saiseikai Kurihashi Hospital, 7|4-6 Koemon Kuki-City, Saitama 349-1 105, Japan

$\mathrm{Tel}+8 \mathrm{I} 4805236 \mathrm{II}$

Fax +8I480520305

Email chikakos@pastel.ocn.ne.jp

\begin{abstract}
We report an unusual case of iris rubeosis and hyphema caused by chemical injury due to household detergent. A 74-year-old man with a 15-year history of diabetes mellitus was refilling a container with household detergent at home. He splashed the detergent in his eyes. Slit-lamp examination revealed extensive epithelial damage to the left eye, leading to a persistent corneal epithelial defect. We used a bandage soft contact lens with levofloxacin eye drops as concomitant therapy in order to promote healing. However, a strain of fluoroquinoloneresistant Corynebacterium colonized the eye, so that the corneal ulcer eventually became severe. Use of the bandage soft contact lens was discontinued. His antimicrobial agent was changed to cefmenoxime, a drug to which fluoroquinolone-resistant Corynebacterium is sensitive, and topical instillation of autologous serum subsequently promoted improvement of the ulcer. On day 38 after injury, iris rubeosis led to hyphema and ghost cell glaucoma. With improvement of his corneal epithelial defect, the iris rubeosis and hyphema regressed and his visual acuity improved to 20/25 on the left eye. To the best of our knowledge, this is the first report of a case resulting in severe complications due to chemical injury by a neutral detergent. Ophthalmologists should be aware that corneal epithelial damage may become prolonged in elderly patients with diabetes, and unexpectedly severe when wearing bandage soft contact lens, with infection of Corynebacterium resistant to fluoroquinolones, even if the chemical agent is a neutral detergent.
\end{abstract}

Keywords: chemical injury, household detergent, persistent corneal epithelial defect, iris rubeosis, fluoroquinolone-resistant Corynebacterium, bandage soft contact lens

\section{Introduction}

Splashing chemicals into the eyes may not only occur as an occupational accident but also while using detergents or other products at home. Most kitchen detergents are neutral ( $\mathrm{pH}$ 6-8) and are mainly composed of a surfactant, a stabilizing agent, and a sequestering agent. Even if a chemical injury occurs, the resulting keratoconjunctival damage is milder in most cases involving a neutral detergent than when an alkaline or acidic agent is the cause. To the best of our knowledge, no severe cases of eye injury caused by a neutral detergent have been reported.

On the other hand, a bandage soft contact lens (SCL) is used for treating a persistent corneal epithelial defect to prevent exfoliation of corneal epithelial cells, to protect from mechanical damage, and to maintain the wettability of the ocular surface. ${ }^{1-6}$ Bacterial contamination using bandage disposable SCL is also reported, ${ }^{7,8}$ and causes bacterial keratitis and infectious endophthalmitis in severe cases..$^{9,10}$

We report a rare case of corneal injury due to a neutral detergent that resulted in a persistent corneal epithelial defect, exhibiting obvious symptoms of intracameral 
inflammation with iris rubeosis and hyphema after wearing a bandage SCL.

\section{Case report}

The patient was a 74-year-old Japanese man who splashed household detergent in his eyes at home in July 2009. He presented with bilateral eye pain and difficulty in opening his eyelids. Because the patient had suffered from diabetes mellitus for 15 years, he had undergone regular examinations for cataract and diabetic retinopathy at our hospital. Before the present injury, there was no diabetic retinopathy and the corrected visual acuity was $20 / 16$ on both sides. At the time of injury, glycosylated hemoglobin was $8.9 \%$ and his antidiabetic drug therapy was limited to glimepiride (Amaryl ${ }^{\circledR}$, Sanofi KK, Paris, France) at $1 \mathrm{mg}$ in the morning. He was not taking an anticoagulant. The substance that entered his eyes was a neutral ( $\mathrm{pH}$ 6.8) detergent (Charmy Awa no Chikara [Power of Suds], Lion Corporation, Tokyo, Japan), the major ingredient of which was a surfactant.

The right eye showed diffuse superficial keratitis, probably because little detergent had splashed into this eye. Hyperemia of the conjunctiva was the main finding and the ocular condition was grade G1 according to the Kinoshita classification. ${ }^{11}$ On the other hand, there was extensive corneal epithelial damage, conjunctival edema, and marked conjunctival hyperemia of the left eye, which was classified as grade G2 according to Kinoshita (Figure 1).

The eyes were irrigated with $2 \mathrm{~L}$ of physiological saline solution for about 20 minutes. Treatment was then started with oral prednisolone, ofloxacin eye ointment, and betamethasone eye ointment. Six days later, the right eye showed almost complete epithelialization and visual acuity had returned to 20/20. However, although the size of the corneal epithelial defect in the left eye was smaller compared with that seen at the initial visit, edema and Descemet's fold were unchanged. At 10 days after injury, reduction of the corneal epithelial defect area was noted in the left eye, but visual acuity was still only hand movement. Because the epithelial defect was still present at 12 days after injury, the patient was given a therapeutic
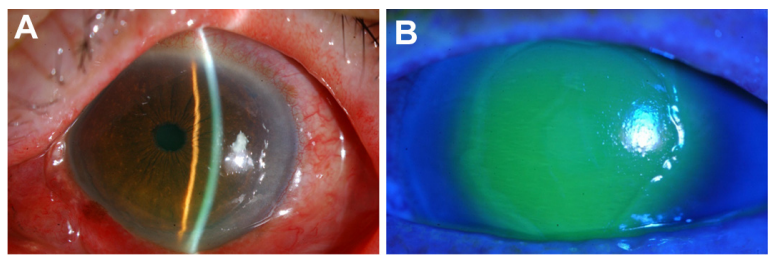

Figure I (A) Slit-lamp photograph showing marked conjunctival hyperemia and conjunctival edema in the left eye. (B) There is an extensive corneal epithelial defect covering almost the entire cornea in the left eye. bandage SCL (Breath-O ${ }^{\circledR}$, Toray Industries Inc, Tokyo, Japan), and treatment was started using an antimicrobial agent $(0.5 \%$ levofloxacin eye drops, Santen Pharmaceutical Co, Ltd, Osaka, Japan), a corticosteroid ( $0.1 \%$ betamethasone eye drops, Shionogi \& Co, Ltd, Osaka, Japan), and sodium hyaluronate eye drops $(0.1 \%$ Hyalein, Santen Pharmaceutical Co, Ltd, Osaka, Japan), four times daily. After 7 days of wearing the bandage SCL, hyperemia was exacerbated and bacterial corneal infiltrates were suspected (Figure 2). Therefore, use of the bandage SCL and topical steroid instillation was discontinued. A Corynebacterium species resistant to fluoroquinolones was detected by culture on rubbing the inferior palpebral conjunctival sac with a sterile cotton swab, so his antimicrobial agent was changed to cefmenoxime, a drug to which fluoroquinolone-resistant Corynebacterium is sensitive. About one month after injury (10 days after starting use of the bandage SCL), the epithelial defect was almost completely resolved, except in a central area with opacity. In addition, corneal epithelial swelling was observed and the endothelial cell density was calculated to be $2237 / \mathrm{mm}^{2}$. Because reepithelialization did not progress, 50\% autologous serum was instilled topically into the eyes. At 38 days after injury, the corneal epithelial defect was healed completely. However, hyphema occurred suddenly, with near-circumferential rubeosis of the iris (Figure 3). The intraocular pressure was around $35 \mathrm{mmHg}$, and ghost cell glaucoma developed. Treatment was started with acetazolamide at a dose of $750 \mathrm{mg} /$ day and a topical long-acting beta-blocker (carteolol hydrochloride, Otsuka Pharmaceutical Co, Ltd, Tokyo, Japan) once a day. About 2 weeks later, the hemorrhage improved and secretions were absorbed, along with a decrease in intraocular pressure and spontaneous regression of rubeosis. Visual acuity was $20 / 100$ in the left eye. After the eye was confirmed to be free from infection, a topical steroid ( $0.02 \%$ fluorometholone eye

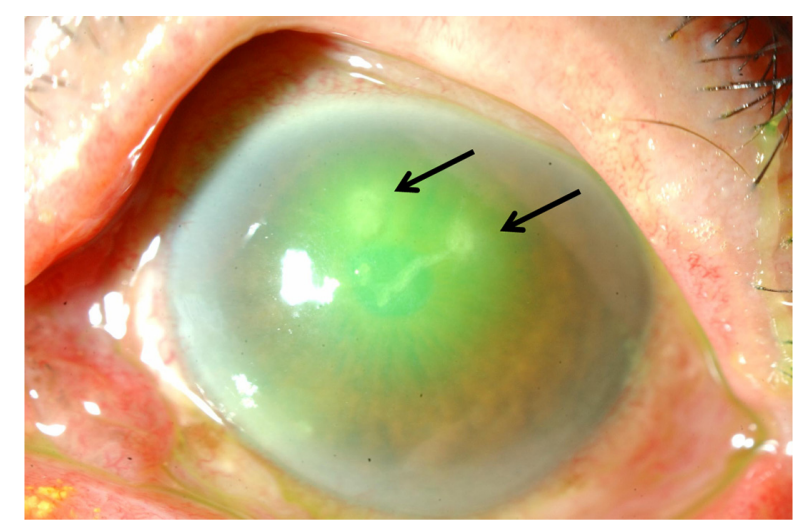

Figure 2 The corneal epithelial defect has become smaller, but it is complicated by infection (arrows) in the left eye. 

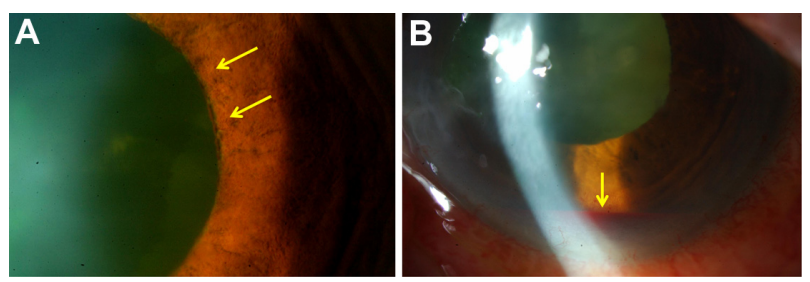

Figure 3 (A) Slit-lamp photograph showing iris rubeosis (arrows) at circumferential pupil margin. (B) There is an obvious hyphema (arrow) in the left eye.

drops, Santen Pharmaceutical Co, Ltd) was administered to clear the opacity in the center of the cornea. At 5 months after injury, his visual acuity improved to $20 / 20$ on the right and 20/25 on the left. Fundus examination of the left eye revealed no diabetic retinopathy, no neovascularization, and normal cupping of the optic disc.

\section{Discussion}

This is a case of hyphema and iris rubeosis following secondary infection of a persistent corneal epithelial defect by Corynebacterium. The condition followed chemical injury by a neutral detergent.

When considering the cause of the onset of iris rubeosis in the present case, it seems highly improbable that rubeosis due to diabetic retinopathy or other ischemic disease would undergo spontaneous remission after such a short time as 2 weeks. We could exclude exacerbation of diabetic retinopathy, internal carotid stenosis, uveitis, retinal ischemia, ophthalmic arteriovenous anomalies, and neoplastic disease.

However, with respect to inflammatory rubeosis like that seen in the present patient, spontaneous regression would be expected to occur with improvement of inflammation. Due to progress with antimicrobial agents, there are no recent reports concerning bacterial corneal ulcers complicated by hyphema and rubeosis. However, there are several reports of microbial keratitis infected by Corynebacterium, especially following use of a bandage $\mathrm{SCL}^{8}$ and after photorefractive keratectomy and laser in situ leratomileusis. ${ }^{12,13}$ Corynebacterium is a genus of Gram-positive, rod-shaped bacteria, which are widely distributed in nature, are mostly innocuous, and constitute one kind of the normal bacterial flora found on the ocular surface. ${ }^{14-16}$ The corneal epithelium is always in contact with the external environment and is likely to come into contact with foreign bodies and pathogens. If there is a corneal epithelial defect, the risk of microbial keratitis will be increased.

Continuous wearing of an SCL is a known risk factor for microbial keratitis. ${ }^{17,18}$ Corneal epithelial damage is present and barrier function is impaired especially in patients who are prescribed a bandage SCL. Because continuous wearing of an SCL results in hypoxia and decreased metabolism in the cornea, this worsens the infectious keratitis already present. In addition, administration of a corticosteroid might have caused the infection to flare. In order to promote healing of the persistent corneal epithelial defect, a bandage SCL was used, with levofloxacin eye drops as concomitant therapy. However, some recent reports from Japan demonstrate a high rate of fluoroquinolone resistance in cases of Corynebacterium. ${ }^{15,16}$ In our case, a strain of fluoroquinolone-resistant Corynebacterium colonized the eye, so that the corneal ulcer eventually became severe and intracameral inflammation also became more severe.

On the other hand, topical instillation of autologous serum subsequently promoted improvement of the ulcer in our case. Jeng et $\mathrm{al}^{19}$ have reported the benefit of topical instillation of autologous serum in patients with persistent corneal epithelial defect, because it has a lower risk of infection and is more useful than a bandage SCL. There is only a remote possibility that topical instillation of autologous serum will cause progression of rubeosis.

What is the mechanism by which rubeosis and hyphema developed in this patient? It would be reasonable to consider that inflammatory cytokines produced in response to chemical injury were responsible for the changes in our patient. Animal studies of alkaline injury have shown a significant increase in interleukin- $1 \alpha$ and interleukin- 6 levels in the cornea ${ }^{20}$ and that bevacizumab (an anti-vascular endothelial growth factor agent) is effective for preventing corneal neovascularization. ${ }^{21}$ It is assumed that, after the initial chemical injury in our patient, persistent corneal ulceration caused by bacterial infection led to severe inflammation and release of the above-mentioned inflammatory cytokines from the corneal stroma into the anterior chamber, thereby increasing the concentration of cytokines in the aqueous humor. Moreover, increased interleukin- $1 \beta$ and interleukin- 6 levels in the retina have been reported following alkaline injury. ${ }^{22}$ In the present case, there is also a possibility that inflammatory cytokines were released from the retina into the vitreous fluid and then transferred to the anterior chamber, thereby causing rubeosis.

Furthermore, irrigation of the eye at home by this patient after the accident was only done for about 5 minutes, which is insufficient. In the future, ophthalmologists as well as emergency physicians and detergent manufacturers must inform the public that at least 15 minutes of irrigation is recommended as initial treatment at the time of injury. 
In conclusion, the message conveyed by this case is that even when chemical injury is due to a neutral detergent, corneal ulceration may be persistent in elderly patients with diabetes who become infected with fluoroquinolone-resistant Corynebacterium, and unexpectedly severe in those wearing a bandage SCL.

\section{Disclosure}

The authors report no conflicts of interest in this work.

\section{References}

1. Gyorffy I. Therapeutic contact-lenses from plastic. Br J Ophthalmol. 1950;34(2):115-118.

2. Kaufman HE, Gasset AR. Therapeutic soft bandage lenses. Int Ophthalmol Clin. 1970;10(2):379-385.

3. Leibowitz HM, Rosenthal P. Hydrophilic contact lenses in corneal disease. II. Bullous keratopathy. Arch Ophthalmol. 1971;85(3):283-285.

4. Leibowitz HM. Hydrophilic contact lenses in corneal disease. IV. Penetrating corneal wounds. Arch Ophthalmol. 1972;88(6):602-606.

5. Karlgard CC, Jones LW, Moresoli C. Survey of bandage lens use in North America, Oct-Dec 2002. Eye Contact Lens. 2004;30(1):25-30.

6. Kudo D, Toshida H, Ohta T, Murakami A. Continuous wear of hydrogel contact lenses for therapeutic use. Open J Ophthalmol. In press.

7. Detorakis ET, Siganos DS, Houlakis VM, Kozobolis VP, Pallikaris IG. Microbiological examination of bandage soft contact lenses used in laser refractive surgery. J Refract Surg. 1998;14(6):631-635.

8. Liu X, Wang P, Kao AA, Jiang Y, Li Y, Long Q. Bacterial contaminants of bandage contact lenses used after laser subepithelial or photorefractive keratectomy. Eye Contact Lens. 2012;38(4):227-230.

9. Beatty S, Tyagi A, Kirkby GR. Klebsiella keratitis complicating bandage contact lens use. Acta Ophthalmol Scand. 1998;76(6):757-758.

10. Ramchandran RS, Diloreto DA Jr, Chung MM, et al. Infectious endophthalmitis in adult eyes receiving Boston type I keratoprosthesis. Ophthalmology. 2012;119(4):674-681.
11. Kinoshita S, Manabe R. Chemical burns. In: Brightbill FS, editor. Corneal Surgery: Theory, Technique, and Tissue. St Louis, MO: Mosby; 1986.

12. De Oliveira GC, Solari HP, Ciola FB, Limal AL, Campos MS. Corneal infiltrates after Excimer laser photorefractive keratectomy and LASIK. $J$ Refract Surg. 2006;22(2):159-165.

13. Garg P, Chaurasia S, Vanddavalli PK, Muralidhar R, Mittal V, Gopinathan U. Microbial keratitis after LASIK. J Refract Surg. 2010;26(3):209-216.

14. Suto C, Morinaga M, Yagi T, Tsuji C, Toshida H. Conjunctival sac bacterial flora isolated prior to cataract surgery. Infect Drug Resist. 2012;5:37-41.

15. Fukumoto A, Sotozono C, Hieda O, Kinoshita S. Infectious keratitis caused by fluoroquinolone-resistant Corynebacterium. Jpn JOphthalmol. 2011;55(5):579-580.

16. Eguchi H, Kuwahara T, Miyamoto T, et al. High-level fluoroquinolone resistance in ophthalmic clinical isolates belonging to the species Corynebacterium macginleyi. J Clin Microbiol. 2008;46(2):527-532.

17. Stapleton F, Dart JK, Minassian D. Risk factors with contact lens related suppurative keratitis. CLAO J. 1993;19(4):204-210.

18. Inoue N, Toshida H, Mamada N, Kogure N, Murakami A. Contact lens-induced infectious keratitis in Japan. Eye Contact Lens. 2007; 33(2):65-69.

19. Jeng BH, Dupps WJ Jr. Autologous serum $50 \%$ eyedrops in the treatment of persistent corneal epithelial defects. Cornea. 2009; 28(10):1104-1108.

20. Sotozono C, He J, Matsumoto Y, Kita M, Imanishi J, Kinoshita S. Cytokine expression in the alkali-burned cornea. Curr Eye Res. 1997;16(7):670-676.

21. Papathanassiou M, Theodossiadis PG, Liarakos VS, Rouvas A, Giamarellos-Bourboulis EJ, Vergados IA. Inhibition of corneal neovascularization by subconjunctival bevacizumub in an animal model. Am J Ophthalmol. 2008;145(3):424-431.

22. Miyamoto F, Sotozono C, Ikeda T, Kinoshita S. Retinal cytokine response in mouse alkali-burned eye. Ophthalmic Res. 1998;30(3):168-171.
Clinical Ophthalmology

\section{Publish your work in this journal}

Clinical Ophthalmology is an international, peer-reviewed journal covering all subspecialties within ophthalmology. Key topics include: Optometry; Visual science; Pharmacology and drug therapy in eye diseases; Basic Sciences; Primary and Secondary eye care; Patient Safety and Quality of Care Improvements. This journal is indexed on Submit your manuscript here: http://www.dovepress.com/clinical-ophthalmology-journal

\section{Dovepress}

PubMed Central and CAS, and is the official journal of The Society of Clinical Ophthalmology (SCO). The manuscript management system is completely online and includes a very quick and fair peer-review system, which is all easy to use. Visit http://www.dovepress.com/ testimonials.php to read real quotes from published authors. 